\title{
APLIKASI PEMBACA DONGENG ANAK INDONESIA BERBASIS ANDROID
}

\author{
Astrid Aprillini $^{1)}$, R. Rizal Isnanto ${ }^{2)}$, Rinta Kridalukmana ${ }^{2)}$ \\ Program Studi Sistem Komputer, Fakultas Teknik, Universitas Diponegoro \\ Jalan Prof. Sudharto, Tembalang, Semarang, Indonesia
}

\begin{abstract}
Currently, to obtain information about fairy tales through a mobile phone is still rare. Readers usually obtain information about fairy tales only through books, CDs or other print media. Of multiple applications on a mobile phone that is only text and images. So the purpose of this study was achieved to help the reader enjoy fairy tales exist in a complicated application without having to read one each one word at story. This study used Luther as a method of multimedia development. There are 6 steps being taken to complete this application, namely the concept stage, design stage, collection materials, manufacture stage, testing stage and distribution. In the testing phase used two kinds of testing, ie testing functions and testing program using the respondents. The results show that “Aplikasi Pembaca Dongeng Anak Indonesia" can display information includes the title story of Indonesian children stories, national origin story, and the story is short but interesting. Can also be a sound and background music on each page of the story based on the story. And the application can be used by users with ease. Based on the results of the questionnaire showed that the data processed $91.76 \%$ positive response or included in the category of "Good".
\end{abstract}

Keywords : fairy tales, mobile phone applications, multimedia development methods

\section{Pendahuluan}

\subsection{Latar Belakang}

Dongeng adalah cerita yang tidak benar-benar terjadi dan dalam banyak hal sering tidak masuk akal. Pendapat lain mengenai dongeng adalah cerita yang tidak benar-benar terjadi, terutama tentang kejadian zaman dulu yang aneh-aneh.

Saat ini untuk memperoleh informasi mengenai dongeng anak melalui telepon seluler masih jarang

1) Mahasiswa Teknik Sistem Komputer

2) Dosen Teknik Sistem Komputer ditemui. Pembaca biasanya memperoleh informasi mengenai dongeng anak hanya melalui buku, CD atau media cetak lainnya. Dari beberapa aplikasi di telepon seluler yang ada hanya menampilkan teks dan gambar.

Hal ini memunculkan ide untuk membuat Aplikasi Pembaca Dongeng Anak Indonesia Berbasis Android. Aplikasi ini dapat digunakan untuk membantu para pembaca menikmati dongeng yang ada dalam aplikasi tanpa harus rumit membaca satu per satu kata isi cerita.

Hasil yang diharapkan dari Aplikasi Pembaca Dongeng Anak Indonesia ini untuk membantu para pembaca menikmati dongeng yang terdiri dari beberapa halaman, dan di setiap halamannya tidak hanya menampilkan teks dongeng tetapi menampilkan gambar dan suara yang membacakan isi teks dongeng.

\subsection{Rumusan Masalah}

Bagaimana menciptakan sebuah "Aplikasi Pembaca Dongeng Anak Indonesia Berbasis Android" yang dapat membantu menampilkan teks dongeng dalam bentuk gambar dan suara dengan musik latar menarik yang membacakan isi teks dongeng tersebut.

\subsection{Batasan Masalah}

Dalam penulisan tugas akhir ini, pembahasan dibatasi dalam hal berikut.

1. Aplikasi perangkat bergerak yang dibangun untuk telepon genggam berbasis Android.

2. Aplikasi ini memiliki 5 (lima) kumpulan dongengdongeng anak Indonesia yang popular.

3. Aplikasi ini hanya menampilkan teks, gambar dan suara dengan musik latar yang membacakan isi cerita tiap halaman.

4. Aplikasi ini bersifat purwarupa (prototipe) sehingga dimungkinkan masih dapat terjadinya kesalahan (bug).

5. Dongeng yang dimaksud adalah dongeng anak yang berasal dari daerah-daerah di Indonesia.

6. Bahasa yang digunakan dalam Aplikasi Pembaca Dongeng Anak adalah Bahasa Indonesia. 


\subsection{Tujuan Tugas Akhir}

Tujuan dari Tugas Akhir ini adalah :

1. Membangun aplikasi perangkat bergerak berbasis Android yang dapat melakukan aktifitas seperti menampilkan gambar beserta teks dongeng dan mengeluarkan suara yang membacakan isi teks dongeng.

2. Membangun aplikasi Android yang ramah pengguna.

3. Diharapkan dapat membangkitkan kembali budaya mendongeng, menumbuhkan minat anak untuk membaca, membantu orangtua untuk mendongeng kepada anak-anaknya, sebagai sarana edukasi, serta meningkatkan kemampuan anak dalam berpikir dan bernalar.

\section{Dasar Teori}

Penelitian yang akan dilakukan berlandaskan pada berbagai teori yang memungkinkan tujuan penelitian dapat tercapai. Teori-teori tersebut menjadi dasar yang membangun penelitian dengan memberikan definisi dan penjabaran yang diperlukan dalam pelaksanaan penelitian, berikut Landasan Teori tersebut.

\subsection{Dongeng}

Dongeng adalah cerita yang tidak benar-benar terjadi dan dalam banyak hal sering tidak masuk akal. Pendapat lain mengenai dongeng adalah cerita yang tidak benarbenar terjadi, terutama tentang kejadian zaman dulu yang aneh-aneh.

Dongeng adalah cerita yang dituturkan atau dituliskan yang bersifat hiburan dan biasanya tidak benar-benar terjadi dalam kehidupan. Dongeng merupakan suatu bentuk karya sastra yang ceritanya tidak benar-benar terjadi/fiktif yang bersifat menghibur dan terdapat ajaran moral yang terkandung dalam cerita dongeng tersebut.

\subsection{Android}

Android adalah sebuah sistem operasi pada telepon genggam yang bersifat terbuka dan berbasis pada sistem operasi Linux. Android bisa digunakan oleh setiap orang yang ingin menggunakannya pada perangkat mereka. Android menyediakan platform terbuka bagi para pengembang untuk menciptakan aplikasi mereka sendiri yang akan digunakan untuk bermacam peranti bergerak. Kelebihan Android adalah :

1. Mudah di Akses (Multitasking).

2. Kemudahan dalam Notifikasi.

3. Akses mudah.

\subsection{HTML5}

HTML5 adalah sebuah bahasa markah untuk menstrukturkan dan menampilkan isi dari World Wide Web (WWW), sebuah teknologi inti dari Internet. HTML5 adalah revisi kelima dari HTML. Tujuan utama pengembangan HTML5 adalah untuk memperbaiki teknologi HTML agar mendukung teknologi multimedia terbaru, mudah dibaca oleh manusia dan juga mudah dimengerti oleh mesin. Berikut tujuan dibuatnya HTML5 :
1. Fitur baru harus didasarkan pada HTML, CSS, dan JavaScript.

2. Mengurangi kebutuhan untuk plugin eksternal (Seperti Flash).

3. Penanganan kesalahan yang lebih baik.

4. HTML5 merupakan perangkat mandiri.

5. Proses pembangunan dapat terlihat untuk umum.

\subsection{JavaScript}

JavaScript adalah bahasa scripting yang popular di internet dan dapat bekerja di sebagian besar browser popoler seperti Internet Explorer (IE), Mozilla Firefox, Netscape dan Opera. Kode Javascript dapat disisipkan dalam halaman web menggunakan tag script. Tag script adalah sebuah skrip yang menunjuk ke suatu file skrip eksternal. Beberapa hal tentang Javascript sebagai berikut.

1. Javascript didesain untuk menambah interaktif suatu web.

2. Javascript merupakan sebuah bahasa scripting.

3. Bahasa scripting merupakan bahasa pemrograman yang ringan.

4. Javascript berisi baris kode yang dijalankan di komputer (web browser).

5. Javascript biasanya disisipkan dalam halaman HTML.

6. Javascript adalah bahasa interpreter (yang berarti skrip dieksekusi tanpa proses kompilasi).

\section{Perancangan Sistem \\ 3.1 Tahapan Pengembangan Multimedia \\ 3.1.1 Konsep}

Media hiburan yang dibuat mempunyai konsep bagaimana menyajikan sebuah cerita dongeng yang interaktif untuk dibaca yang dapat membantu anak dan orang tua. Dengan dibuatnya media hiburan interaktif, anak dapat lebih tertarik untuk membaca dongeng, proses membaca dapat dilakukan secara mandiri, dan anak dapat memahami isi cerita dengan lebih cepat. Bagi orang tua dengan adanya media hiburan maka orang tua tidak lagi menceritakan cerita dongeng secara manual, artinya orang tua hanya menjadi fasilitator ketika ada isi cerita yang belum dimengerti saja. Isi cerita yang akan disajikan dalam media hiburan ini adalah cerita dongeng anak Indonesia.

\subsubsection{Perancangan}

Terdapat 3 (tiga) macam jenis perancangan yaitu perancangan aplikasi, perancangan bagan alir dan perancangan tampilan.

Tahap awal dalam perancangan dibuat sebuah bagan perancangan dari keseluruhan aplikasi. Bagan perancangan aplikasi ditunjukkan oleh Gambar 3.1. 


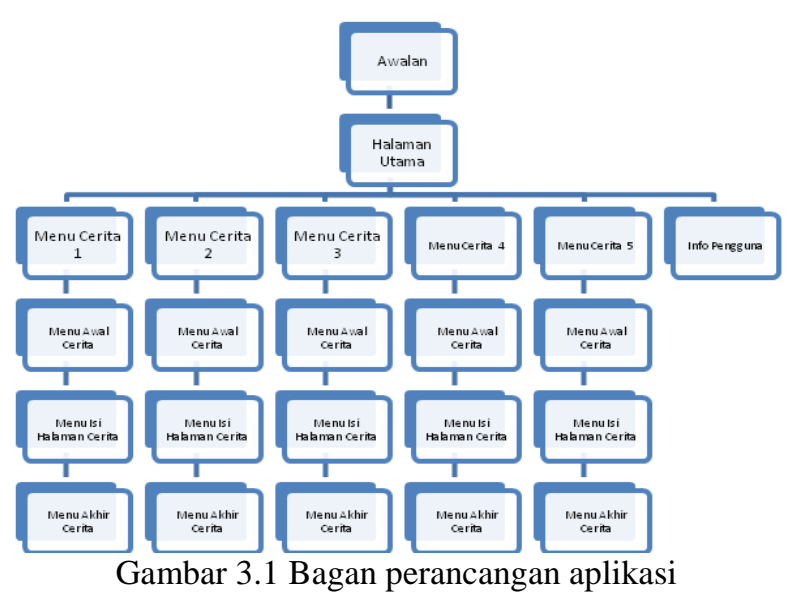

Setelah pembuatan bagan perancangan aplikasi yang dimana dapat menjelaskan bagian-bagian dari aplikasi, maka dilanjutkan dengan pembuatan bagan alir (flowchart) yang menjelaskan alur program yang dibuat. Aplikasi yang dibuat mempunyai 2 (dua) menu utama yaitu menu Cerita dan menu Info Pengguna. Bagan alir pada halaman utama aplikasi ditunjukkan oleh Gambar 3.2 .

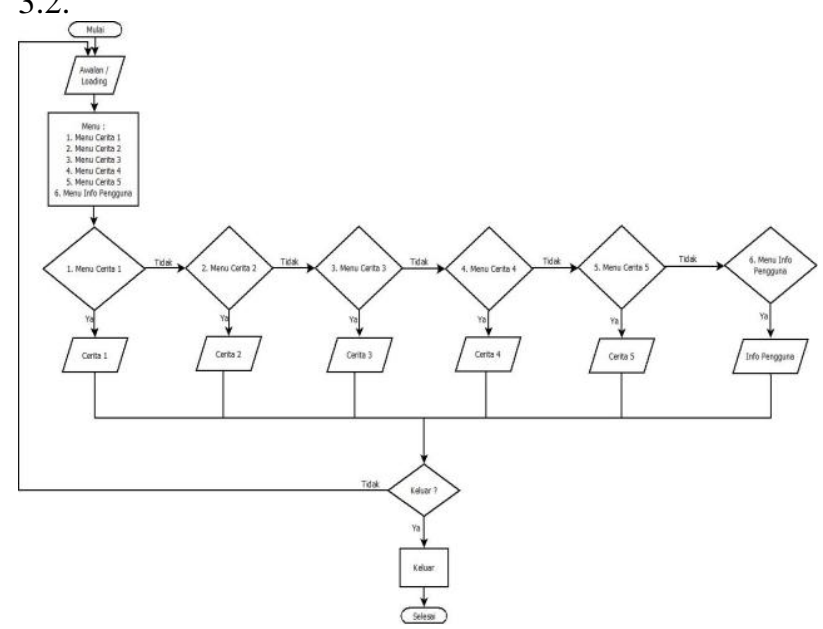

Gambar 3.2 Bagan alir halaman utama

Terdapat 5 (lima) menu Cerita berisi macammacam cerita dongeng anak Indonesia yang akan menampilkan gambar dari tiap halaman isi cerita. Bagan alir pada menu Awal Cerita ditunjukkan oleh Gambar 3.3.

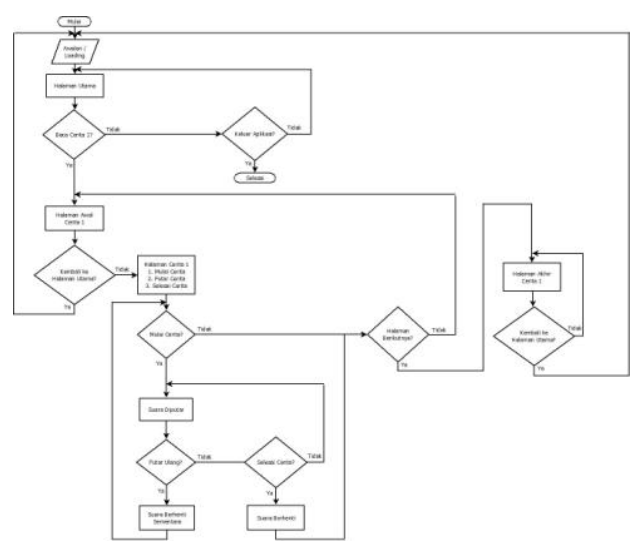

Gambar 3.3 Bagan alir menu cerita

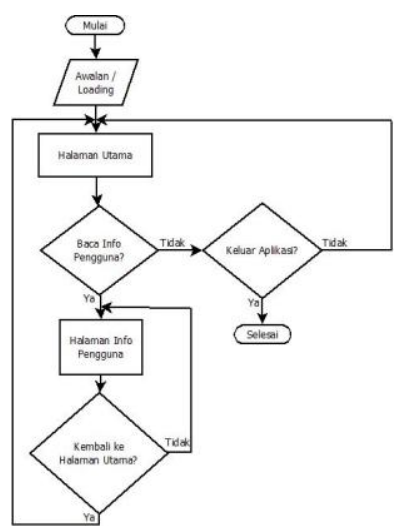

Gambar 3.4 Bagan alir menu info pengguna

Menu Info Pengguna berisi gambar dan informasi cara menggunakan aplikasi seperti informasi tomboltombol pada aplikasi. Bagan alir pada menu Info Pengguna ditunjukkan oleh Gambar 3.4.

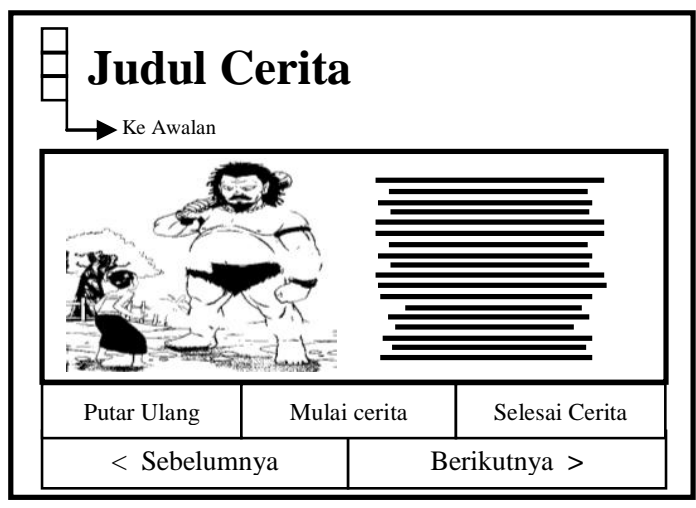

Gambar 3.4 Tampilan menu isi halaman cerita

\section{Hasil Penelitian dan Pembahasan}

\subsection{Hasil Penelitian}

Pembuatan aplikasi ini menggunakan metodologi Luther yang sudah di modifikasi oleh Sutopo. Ada 6 tahapan yang dilakukan untuk menyelesaikan aplikasi ini, yaitu tahap konsep, desain, pengumpulan materi, pembuatan, pengujian dan distribusi. Setelah aplikasi selesai dikerjakan, untuk proses distribusinya aplikasi ini dikonversi dalam bentuk .apk dan hanya aplikasi .apk ini yang diujikan.

Berikut merupakan tampilan aplikasi yang dibuat.

\section{Tampilan awal aplikasi}

Ketika aplikasi ini pertama dijalankan maka akan mulai tampilan-tampilan awalan seperti judul skripsi, nama dan NIM mahasiswa, jurusan, fakultas dan universitas dimana mahasiswa bersekolah dan logo Android. Contoh tampilan awal aplikasi ditunjukkan oleh Gambar 4.1. 


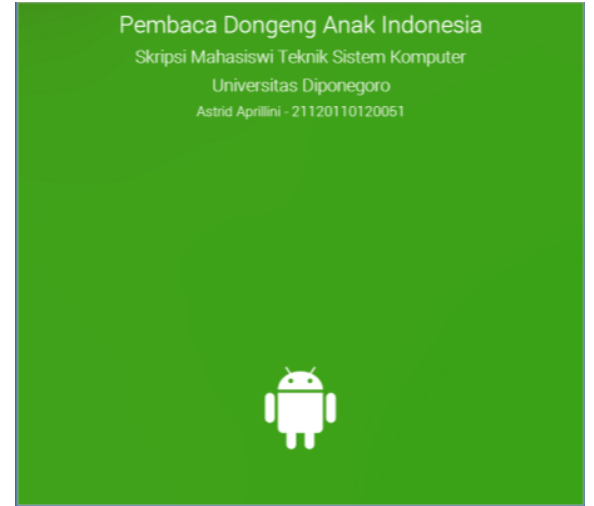

Gambar 4.1 Tampilan awal aplikasi

\section{Tampilan halaman utama}

Aplikasi ini mempunyai 6 (enam) menu yang berisi 5 (lima) menu Cerita dan menu Info Pengguna. Contoh tampilan halaman utama ditunjukkan oleh Gambar 4.2.

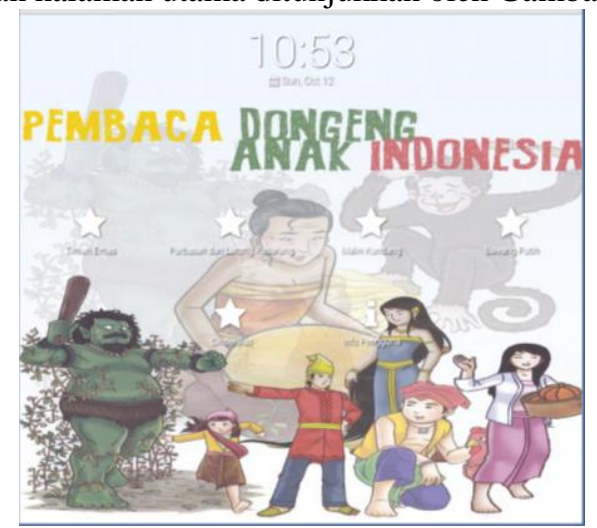

Gambar 4.2 Tampilan halaman utama

\section{Tampilan isi masing-masing menu}

Isi dari keenam menu terdapat 5 (lima) menu yang sama dan 1 (satu) menu berbeda. Berikut tampilan dari menu-menu yang ada.

\section{a. Menu Cerita}

Pada awal menu cerita ditampilkan gambar penuh dengan judul dan asal daerah cerita. Terdapat dua tombol yaitu tombol Menu dan Baca Cerita. Saat tombol Menu diklik maka tampilan akan kembali ke halaman utama, namun saat tombol Baca Cerita diklik maka tampilan akan memulai halaman isi cerita. Salah satu contoh tampilan isi menu awal cerita dapat ditujukkan pada Gambar 4.3.

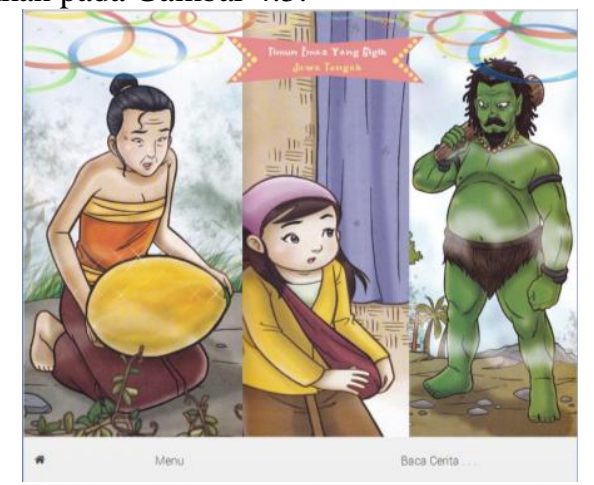

Gambar 4.3 Tampilan menu awal cerita 1
Saat tombol Baca Cerita diklik maka tampilan akan memulai halaman isi cerita halaman pertama. Pada halaman isi cerita terdapat 5 (lima) tombol yaitu Putar Ulang, Mulai Cerita, Selesai Cerita, Sebelumnya dan Berikutnya. Dengan melakukan klik pada tombol Mulai Cerita maka halaman isi cerita akan memutarkan suara berupa isi cerita dari halaman tersebut. Tombol Putar Ulang untuk memberhentikan sementara suara cerita yang sedang diputar dan tombol Selesai Cerita untuk memberhentikan suara cerita. Untuk kembali ke halaman cerita sebelumnya klik tombol Sebelumnya dan untuk melanjutkan halaman cerita klik tombol Berikutnya. Salah satu contoh menu isi halaman cerita dapat ditujukkan pada Gambar 4.4.

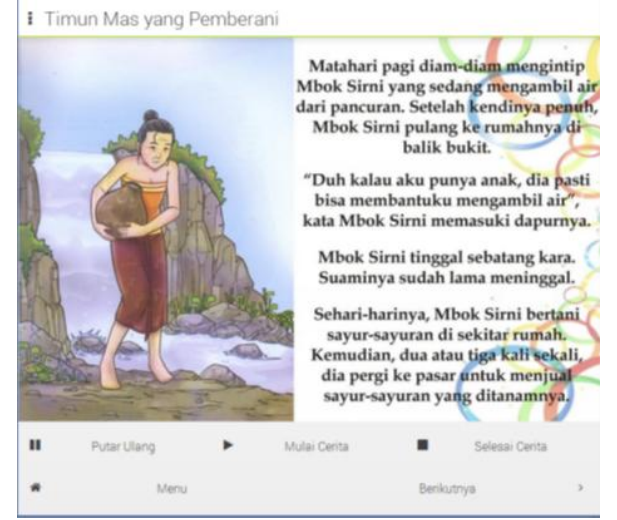

Gambar 4.4 Tampilan menu isi halaman cerita 1

Tampilan menu akhir cerita berisi tampilan dengan tulisan tamat yang berarti bahwa cerita telah berakhir dan terdapat tombol Menu untuk kembali ke halaman utama. Contoh tampilan isi menu isi cerita halaman tengah ditunjukkan oleh Gambar 4.5.

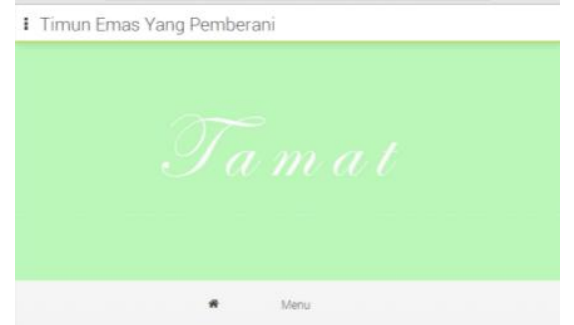

Gambar 4.5 Tampilan menu akhir cerita

\section{b. Menu Info Pengguna}

Pada menu info pengguna terdapat tampilan gambar contoh halaman cerita yang diberi tanda berupa angka. Angka tersebut lalu di jelaskan dengan kata-kata yang berisi informasi fungsi dari tiap tombol pada aplikasi. Contoh tampilan menu info pengguna ditunjukkan oleh Gambar 4.6.

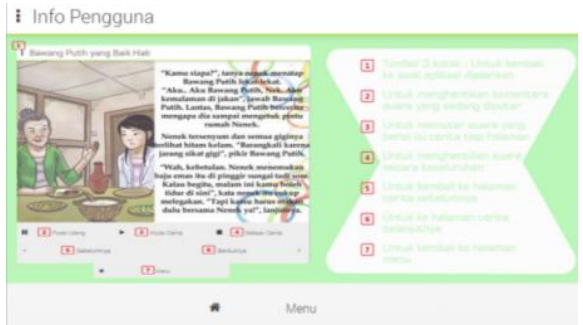

Gambar 4.6 Tampilan menu info pengguna 
4.2. Pengujian aplikasi menggunakan Pengujian Kotak-Hitam (Black-Box Test)

Pengujian ini dilakukan untuk menunjukkan fungsi program yang dibuat tentang cara operasi dan kegunaannya, apakah keluaran data sesuai dengan yang diharapkan. Pengujian ini dilakukan untuk mengetahui apakah masih terjadi kesalahan program atau program sudah berhasil diselesaikan dengan benar.

Pengujian aplikasi dibuat berupa tabel-tabel Pengujian Kotak-Hitam dari masing-masing menu yang ada dalam aplikasi.

\section{Pengujian pada aplikasi secara keseluruhan}

Berikut tabel pengujian pada aplikasi secara keseluruhan ditunjukkan oleh Tabel 4.1.

Tabel 4.1 Tabel pengujian aplikasi secara keseluruhan

\begin{tabular}{|c|c|c|c|}
\hline Nama Pengujian & $\begin{array}{c}\text { Bentuk } \\
\text { Pengujian }\end{array}$ & Hasil yang Diharapkan & $\begin{array}{c}\text { Hasil } \\
\text { Pengujian }\end{array}$ \\
\hline Loading & Membulka aplikasi & $\begin{array}{c}\text { Tampilan logo Android dan } \\
\text { tokoh cerita rakyat }\end{array}$ & Berhasil \\
\hline $\begin{array}{c}\text { Pengujian menu } \\
\text { Cerita }\end{array}$ & $\begin{array}{c}\text { Mengllik kotak } \\
\text { menu Cerita }\end{array}$ & $\begin{array}{c}\text { Tampil gambar dengan telss } \\
\text { isi Cerita yang dibagi tiap } \\
\text { halaman dan suara yang } \\
\text { dapat diputar }\end{array}$ & Berhasil \\
\hline $\begin{array}{c}\text { Pengujian menu } \\
\text { Info Pengguna }\end{array}$ & $\begin{array}{c}\text { Mengllik kotak } \\
\text { menu Info } \\
\text { Pengguna }\end{array}$ & $\begin{array}{c}\text { Tampil gambar dengan teks } \\
\text { berisi informasi fungsi } \\
\text { tombol-tombol untuk } \\
\text { menjalankan splikasi }\end{array}$ & Berhasil \\
\hline
\end{tabular}

\section{Pengujian pada menu Cerita}

Berikut tabel pengujian pada menu Cerita ditunjukkan oleh Tabel 4.2.

Tabel 4.2 Pengujian menu cerita

\begin{tabular}{|c|c|c|c|c|}
\hline Nama Pengujian & $\begin{array}{c}\text { Bentulk } \\
\text { Pengujian }\end{array}$ & \multicolumn{2}{|c|}{ Hasil yang Diharapkan } & $\begin{array}{c}\text { Hasil } \\
\text { Pengujian }\end{array}$ \\
\hline $\begin{array}{l}\text { Pengujian menu } \\
\text { Cerita }\end{array}$ & $\begin{array}{l}\text { Mengklik kotak } \\
\text { menu Cerita }\end{array}$ & \multicolumn{2}{|c|}{$\begin{array}{l}\text { Tampil gambar dengan tels isi } \\
\text { cerita yang dibagi tiap halaman } \\
\text { dan suara yang dapat diputar }\end{array}$} & Berhasil \\
\hline $\begin{array}{c}\text { Pengujian tombol } \\
\text { Menu }\end{array}$ & $\begin{array}{l}\text { Mengklik tombol } \\
\text { Menu }\end{array}$ & \multicolumn{2}{|c|}{$\begin{array}{c}\text { Tampilan kembali ke halaman } \\
\text { utama }\end{array}$} & Berhasil \\
\hline $\begin{array}{l}\text { Pengujian tombol } \\
\text { Sebelunnya }\end{array}$ & $\begin{array}{l}\text { Mengklik tombol } \\
\text { Sebelumnya }\end{array}$ & \multicolumn{2}{|c|}{$\begin{array}{l}\text { Tampilan kembali ke halaman } \\
\text { cerita sebelumnya }\end{array}$} & Berhasil \\
\hline $\begin{array}{l}\text { Pengujian tombol } \\
\text { Berikutnya }\end{array}$ & $\begin{array}{l}\text { Mengklik tombol } \\
\text { Berikutnya }\end{array}$ & \multicolumn{2}{|c|}{$\begin{array}{c}\text { Tampilan ke halaman cerita } \\
\text { berikutnya }\end{array}$} & Berhasil \\
\hline $\begin{array}{l}\text { Pengujian } \\
\text { tombol Mulai } \\
\text { Cerita }\end{array}$ & \multicolumn{2}{|c|}{$\begin{array}{c}\text { Menglelik tombol Mulai } \\
\text { Cerita (dengan simbol Play } \\
\text { button) }\end{array}$} & $\begin{array}{l}\text { Suara isi cerita akan } \\
\text { mulai berputar }\end{array}$ & Berhasil \\
\hline $\begin{array}{l}\text { Pengujian } \\
\text { tombol Putar } \\
\text { Ulang }\end{array}$ & \multicolumn{2}{|c|}{$\begin{array}{c}\text { Mengklik tombol Putar } \\
\text { Ulang (dengan simbol Pause } \\
\text { button) }\end{array}$} & $\begin{array}{l}\text { Suara isi cerita berhenti } \\
\text { untuk sementara }\end{array}$ & Berhasil \\
\hline $\begin{array}{c}\text { Pengujian } \\
\text { tombol Selesai } \\
\text { Cerita }\end{array}$ & \multicolumn{2}{|c|}{$\begin{array}{c}\text { Mengklik tombol Selesai } \\
\text { Cerita (dengan simbol Stop } \\
\text { button) }\end{array}$} & $\begin{array}{l}\text { Suara isi cerita alkan } \\
\text { berhenti }\end{array}$ & Berhasil \\
\hline $\begin{array}{l}\text { Pengujian } \\
\text { tombol Back }\end{array}$ & \multicolumn{2}{|c|}{$\begin{array}{l}\text { Menglklik tombol back pada } \\
\text { bagian atas yang terdapat } 3 \\
\text { kotak ajijar horizontal } \\
\text { (tombol paling kiri atas) }\end{array}$} & $\begin{array}{l}\text { Mengulang aplikasi dari } \\
\text { awal (loading kembali } \\
\text { lalu ke menu utama) }\end{array}$ & Berhasil \\
\hline
\end{tabular}

\section{Pengujian pada menu Info Pengguna}

Berikut tabel pengujian pada menu Info Pengguna ditunjukkan oleh Tabel 4.3.
Tabel 4.3 Pengujian menu info pengguna

\begin{tabular}{|c|c|c|c|}
\hline $\begin{array}{c}\text { Nama } \\
\text { Pengujian }\end{array}$ & Bentuk Pengujian & $\begin{array}{c}\text { Hasil yang } \\
\text { Diharapkan }\end{array}$ & $\begin{array}{c}\text { Hasil } \\
\text { Pengujian }\end{array}$ \\
\hline $\begin{array}{c}\text { Pengujian } \\
\text { menu Info } \\
\text { Pengguna }\end{array}$ & $\begin{array}{c}\text { Mengklik kotak menu Info } \\
\text { Pengguna }\end{array}$ & $\begin{array}{c}\text { Tampil gambar dengan } \\
\text { teks berisi informasi } \\
\text { fungsi tombol-tombol }\end{array}$ & Berhasil \\
\hline $\begin{array}{c}\text { Pengujian } \\
\text { tombol Back }\end{array}$ & $\begin{array}{c}\text { Menglllik tombol back pada } \\
\text { bagian atas yang terdapat 3 } \\
\text { kotak sejajar horizontal } \\
\text { (tombol paling kiri atas) }\end{array}$ & $\begin{array}{c}\text { Mengulang aplikasi dari } \\
\text { awal (loading kembali } \\
\text { lalu ke menu utama) }\end{array}$ & Berhasil \\
& & \\
& & & \\
& & &
\end{tabular}

\subsection{Analisis hasil pengujian aplikasi menggunakan} kuesioner

Studi kasus dalam pengujian aplikasi ini adalah anak-anak di daerah Tambakrejo, Semarang. Dalam pelaksanaannya aplikasi dijalankan oleh masing-masing anak dan setelah semua anak mencoba aplikasinya kemudian diberikan kuesioner yang digunakan untuk mendapatkan data dari responden tentang aplikasi yang dibuat. Kuesioner berisi 10 pertanyaan. Dari hasil kuesioner yang sudah didapat, kemudian data diolah dan disajikan dalam bentuk tabel agar dapat mudah dibaca.

Terdapat 2 (dua) tahap pertanyaan yaitu fingsionalitas aplikasi dan antarmuka dan pengaksesan aplikasi. Masing-masing tahap terdapat 5 (lima) jenis pertanyaan. Pengujian dengan kuesioner dapat ditujukkan pada Tabel 4.4 dan Tabel 4.5.

Tabel 4.4 Tabel hasil pengujian dengan kuesioner

\begin{tabular}{|c|c|c|c|}
\hline No & Pertanyaan & Jumlah & $\%$ \\
\hline 1 & $\begin{array}{c}\text { Aplikasi dapat } \\
\text { menampilkan gambar } \\
\text { dan teks cerita sesuai } \\
\text { dengan judul pada menu } \\
\text { utama }\end{array}$ & 113 & 90,4 \\
\hline 2 & $\begin{array}{c}\text { Aplikasi dapat } \\
\text { mengeluarkan suara } \\
\text { sesuai dengan halaman } \\
\text { yang ditampilkan dengan } \\
\text { menekan tombol Mulai } \\
\text { Cerita }\end{array}$ & 117 & 93,6 \\
\hline 3 & $\begin{array}{c}\text { Aplikasi dapat } \\
\text { menghentikan suara } \\
\text { sementara yang sedang } \\
\text { berlangsung dengan } \\
\text { menekan tombol Putar } \\
\text { Ulang }\end{array}$ & 114 & 91,2 \\
\hline 4 & $\begin{array}{c}\text { Aplikasi dapat } \\
\text { menghentikan suara } \\
\text { dengan menekan tombol } \\
\text { Selesai Cerita }\end{array}$ & 115 & 92 \\
\hline 5 & $\begin{array}{c}\text { Apliaksi dapat } \\
\text { menampilkan menu info } \\
\text { pengguna }\end{array}$ & 112 & 89,6 \\
\hline 6 & $\begin{array}{c}\text { Apliaksi mudah } \\
\text { digunakan }\end{array}$ & 120 & 96 \\
\hline 7 & $\begin{array}{l}\text { Pemilihan warna } \\
\text { antarmuka sudah tepat }\end{array}$ & 121 & 96,8 \\
\hline
\end{tabular}


Tabel 4.5 Tabel hasil pengujian dengan kuesioner (lanjutan)

\begin{tabular}{|c|c|c|c|}
\hline No & Pertanyaan & Jumlah & $\%$ \\
\hline 8 & $\begin{array}{c}\text { Bahasa yang digunakan } \\
\text { mudah dipahami }\end{array}$ & 117 & 93,6 \\
\hline 10 & $\begin{array}{c}\text { Aplikasi memutar suara } \\
\text { dengan jelas dan mudah } \\
\text { dipahami }\end{array}$ & 110 & 88 \\
\hline $\begin{array}{c}\text { Apliaksi menampilkan } \\
\text { teks cerita dengan jelas }\end{array}$ & 108 & 86,4 \\
\hline
\end{tabular}

\subsection{Pembahasan}

Hasil pengujian aplikasi menggunakan metode Pengujian Kotak-Hitam, menunjukkan bahwa sistem sudah berjalan sesuai dengan spesifikasi kebutuhan dan perancangan aplikasi. Hal ini ditunjukkan oleh Tabel 4.1 sampai dengan Tabel 4.4 yang menampilkan hasil uji "Berhasil" pada tiap fungsi aplikasi dan tombol. Secara fungsional, sistem sudah dapat menghasilkan keluaran yang diharapkan.

Berdasarkan hasil olah data kuesioner didapat skor rata-rata dari semua pertanyaan yaitu sebesar 91,76\%. Hasil pada Tabel 4.5 sampai dengan Tabel 4.14 menunjukkan bahwa lebih dari $75 \%$ jawaban kuesioner berisi jawaban positif, atau dapat dikatakan sistem yang dibuat sudah berhasil dengan baik.

Berdasarkan hasil olah data kuesioner, didapat pula rincian bahwa lebih dari $90 \%$ responden menjawab SS atau Sangat Setuju pada 7 (tujuh) dari 10 (sepuluh) pertanyaan yang diberikan. Alasan responden adalah karena aplikasi memiliki tampilan yang sangat menarik dan mudah untuk digunakan. Tampilan gambar yang berwarna dan suara dengan musik latar yang menarik membuat responden tidak bosan untuk membaca cerita anak yang ada pada aplikasi. Sedangkan 3 (tiga) dari 10 (sepuluh) pertanyaan mendapat hasil lebih dari $85 \%$ yaitu responden menjawab $\mathrm{S}$ atau Setuju.

Seperti dalam batasan masalah, bahwa aplikasi ini akan dijalankan pada perangkat bergerak Android. Setelah dilakukan pengujian, aplikasi ini berjalan dengan baik pada perangkat bergerak Android.

Keseluruhan dari hasil olah data kuesioner dapat disimpulkan bahwa aplikasi yang dibuat telah memenuhi syarat kelayakan yang sudah ditentukan sebelumnya dan dapat direkomendasikan untuk didistribusikan kepada Play Store Android dalam bentuk file .apk untuk memanfaatkan media hiburan interaktif dalam proses pembelajaran cerita dan budaya Indonesia sebagai alternatif pembelajaran yang menyenangkan.

\section{Penutup}

\subsection{Kesimpulan}

Dari hasil pengujian dan analisis Aplikasi Pembaca Dongeng Anak Indonesia Berbasis Android dapat disimpulkan beberapa hal berikut :

1. Aplikasi Pembaca Dongeng Anak Indonesia sudah dapat menampilkan informasi cerita anak Indonesia meliputi judul cerita, asal daerah cerita, dan isi cerita yang singkat namun menarik.
2. Aplikasi Pembaca Dongeng Anak Indonesia sudah dapat mengeluarkan suara dan musik latar di tiap halaman cerita sesuai isi cerita tersebut.

3. Aplikasi dapat digunakan oleh pengguna dengan mudah karena aplikasi dirancang untuk anak-anak sesuai dengan proses yang ada sehingga mempermudah proses adaptasi.

4. Rata-rata skor dari seluruh hasil kuesioner adalah 91,76\% atau termasuk dalam kategori "Baik".

5. Berdasarkan hasil olahan data kuesioner menunjukkan bahwa $75 \%$ lebih jawaban positif, artinya lebih dari $75 \%$ menjawab Setuju (S) dan Sangat Setuju (SS) pada pertanyaan kuesioner.

\subsection{Saran}

1. Perlu dilakukan penelitian lebih lanjut untuk mengembangkan Aplikasi Pembaca Dongeng Anak Indonesia agar tidak sekedar berisi tampilan cerita dan suara yang memutar isi cerita tetapi juga menampilkan permainan atau kuis yang dapat menambah wawasan anak tentang cerita anak Indonesia.

2. Perlu dilakukan penelitian lebih lanjut untuk mengembangkan Aplikasi Pembaca Dongeng Anak Indonesia agar dilengkapi dengan musik latar (backsound) di keseluruhan aplikasi sehingga ketika dijalankan, aplikasi lebih menarik.

3. Perlu dilakukan penelitian lebih lanjut untuk mengembangkan Aplikasi Pembaca Dongeng Anak Indonesia yang memiliki kemampuan untuk dapat mengakses aplikasi tanpa koneksi Internet.

4. Perlu dilakukan penelitian lebih lanjut untuk mengembangkan Aplikasi Pembaca Dongeng Anak Indonesia dengan membuat basis data (database) untuk menyimpan gambar dan juga suara dari masing-masing halaman isi cerita agar akses aplikasi lebih cepat dan mudah.

5. Perlu dilakukan penelitian lebih lanjut untuk mengembangkan Aplikasi Pembaca Dongeng Anak Indonesia dengan menambahkan lebih banyak macam-macam cerita anak Indonesia.

\section{DAFTAR PUSTAKA}

[1] Ariesto Hadi, Sutopo. 2003. Multimedia Interaktif dan Flash. PT Graha Ilmu, Yogyakarta.

[2] Badudu, Yus. 1983. Sari Kesusasteraan Indonesia. Pustaka Prima, The University of Machigan, US.

[3] H.Nazruddin. 2012. Programming Mobile Smartphone and Tablet Applications Android-based PC. Informatika, Bandung.

[4] Hana, Jasmin. 2011. Terapi Kecerdasan Anak dengan Dongeng. Berlian Media, Yogyakarta.

[5] Hunter, David et al. 2007. Beginning XML, Fourth Edition. Wiley Publishing, Inc.Indiana.

[6] Kamisa. 1997. Indonesian Dictionary. PT Library Main Grafindo, Surabaya. 
[7] Likert, Rensis. 1932. A Technique for the Measurement of Attitudes. Archives of Psychology 140. The University of Machigan, US.

[8] Raharjo, Budi. 2010. Mudah Belajar Java. Informatika, Bandung.

[9] Riyanto, Slamet. 2010. Membuat Web Portal Multi Bahasa Jomla 1.5X + CD. Elex Media Komputindo. Indonesia.

[10]Sigit W., Aloysius. 2011. Website Super Canggih denagn Plugin jQuery Terbaik. Mediakita, Jakarta.

[11]Sunyoto, Andi. 2007. Ajax Membangun Web dengan Teknologi Asynchronouse Javascript \& XML. Penerbit Andi Offset, Yogyakarta.
[12]Tim Penyusun Pusat Kamus. 2007. Kamus Besar Bahasa Indonesia (KBBI). Balai Pustaka, Indonesia.

[13]Whitten, Jefrey L., Bentley, Lonnie D. 2007). System Analysis and Design Method - 7th. ed.McGraw-Hill. US.

[14]Williams, Laurie. 2006. Testing Overview and Black-Box Testing Techniques. North Carolina State University.

15]Williard, Wendy. 2006. HTML: A Beginner's Guide, Fifth Edition. Mcgraw-Hill Osborne Media. US.

[16Wirjosuparto, R. M. Sutjipto. 1964. Glimpses Of Cultural History Of Indonesia. Indira, US. 